\title{
Diagnosis of dyslexia by means of a new indicator of eye dominance
}

\author{
J. F. STEIN ${ }^{1}$ AND S. FOWLER \\ From the 'University Laboratory of Physiology, Oxford, and the ${ }^{2}$ Ophthalmology \\ Department, Royal Berkshire Hospital, Reading
}

SUMMARY Many dyslexic children are unable accurately to control the movements of their eyes even when they are not trying to read. This immaturity helps to explain their visual confusions. It may result from failure to develop dependable associations between retinal and ocular motor signals. These are essential to fix the true, as opposed to retinotopic, locations of objects in the outside world. We have used a new test to study retinal/ocular motor correspondence in dyslexic children and age/IQ matched normal readers. Over half the dyslexics showed unstable ocular motor dominance.

The idea that developmental dyslexia is ever the result of a primary visual disorder is not at present popular because conventional tests rarely reveal any disorder of a dyslexic's eyesight, while thousands of children with profoundly abnormal vision nevertheless learn to read successfully. Dyslexia is generally held to be a general cognitive defect rather than a perceptual one. ${ }^{1}$

Dyslexia is, however, often associated with abnormal movements of the eyes. ${ }^{23}$ Although many people suggest that these are merely a consequence rather than a cause of reading difficulties, perhaps arising from children's inability to make sense of what they see, ${ }^{4}$ it is now clear that many dyslexics have unusual eye movements even when they are not trying to read.

They are more likely than normal readers to show esophoria, ${ }^{5}$ convergence insufficiency, ${ }^{6}$ breakdown to saccadic jerks (cogwheeling) during attempts at smooth pursuit, ${ }^{7}$ excessive numbers of regressions, and inability to maintain stable fixation when viewing sequentially illuminated light-emitting diodes. ${ }^{8}$

These eye movement disorders may help to explain a child's difficulties with learning to read. Reading demands highly accurate ocular motor control, together with precise monitoring of eye position, since this is essential to determine true visual direction. When we look at a letter we can estimate its true position in space only if we know the exact angle of our gaze. The positions of the images of the letter Correspondence to Dr J. Stein, University Laboratory of Physiology, Parks Road, Oxford OX1 3PT. on the retinae do not reveal its correct direction in relation to the observer unless the direction in which the eyes are pointing at the time is known precisely. Retinotopic co-ordinates must be transformed into real space co-ordinates by means of extraretinal signals about eye position. Such signals are generated by the ocular motor system in the course of achieving accurate eye movements; they are then associated with retinal signals about an object in order to determine its exact whereabouts.

Monitoring of eye position is of course necessary long before reading begins, but to read successfully a new degree of precision is demanded. Dyslexics tend to lose their place on a page, and for them letters often seem to move around and reverse themselves. It is possible therefore that they fail to develop sufficiently accurate ocular motor control, and hence lack sufficient information about the direction of their gaze, to tell them precisely where their eyes are pointing when they are trying to read.

Precise movements of the eyes and hence reliable monitoring of their position may depend on the development of ocular motor dominance. ${ }^{9}$ If the eyes are converged for near vision as when reading, the position of each eyeball is different; hence each may provide different ocular motor signals about the true direction of the same object in the outside world. To prevent confusion we probably learn to attend to the extraretinal position signals of only one eye when assessing visual direction. ${ }^{1011}$ The successful development of this habit in relation to foveal vision 332 
duplicated representation of the fovea and probably of the eye movements relating to it, in both visual cortices, ${ }^{1213}$ enhances the possibility of unreliable associations between retinal and ocular motor signals dealing with this region of the retina. Dyslexia may therefore sometimes be associated with failure to develop consistent dominance of one eye's ocular motor signals. This may lead to confusion about precisely where words and letters are positioned on a page.

Unfortunately monocular indicators of eye dominance, such as the eye preferred for using a telescope, or binocular measures relating to distance vision, such as the 'sighting eye' test, probably fail to indicate whether reliable association of the ocular motor and retinal signals which deal with foveal vision during convergence has been achieved. ${ }^{614-16}$ The problem when reading, which the development of ocular motor dominance of one eye helps to solve, is that of defining visual direction when the eye position signals provided by each eye disagree. A test for eye dominance should therefore establish such conflict, if it is to be relevant to the diagnosis of dyslexia. Then, if it is shown that the associations made by ocular motor and retinal signals deriving from each eye are variable, we may conclude that the subject has failed to achieve reliable ocular motor dominance.

We have therefore modified an orthoptic test, introduced by Dunlop, ${ }^{5}$ in order to provide conditions in which the retinal and ocular motor signals furnished by each eye do not agree with each other. We have used this test in a double-blind study of dyslexics and normal readers, and here show that 'visual' dyslexics fail to develop reliably lateralised ocular motor dominance.

\section{Subjects and methods}

Eighty children (69 boys) were referred to the Ophthalmology Department of the Royal Berkshire Hospital from 2 centres in Reading which took children with reading problems from local primary schools. We classified them as 'dyslexic' because despite having a normal performance intelligence quotient (IQ) (WISC $>90$ ) their reading age (using the Neale analysis of reading accuracy) was more than 18 months behind their chronological age. We compared the dyslexics with 80 normal readers matched according to age and performance IQ drawn from the same schools. Children were excluded if they had a history of neurological, psychiatric, or social problems.

Each child was assessed by remedial teachers according to the type of reading errors he or she made. Although these assessments were perforce subjective, attempting to indicate for teaching purposes the nature of the children's reading errors as 'visual' or 'nonvisual', neither we nor the children were informed who had been classified as dyslexic, whether visual or nonvisual, until after we had completed our ocular examinations.

We also studied a further 274 children with similar reading difficulties but for whom we do not have detailed IQ, reading age or reading error assessments.

CLINICAL EXAMINATION

A complete medical history was taken from all 434 children. Each was given ophthalmological and orthoptic examinations. The children were all asked which hand they used for writing and which foot they used for kicking; and each performed the Dunlop test 10 times.

\section{DUNLOP TEST}

The child viewed through a synoptophore 2 macular sized fusion slides (Clement Clark F9 and F10) showing a house with a central front door and different sized trees as controls. In the slide viewed by the right eye a small tree was drawn on the left of the front door; in that viewed by the left eye a large tree was placed to its right. Thus the trees were viewed in the nasal field of each eye and were therefore initially projected to the visual cortex ipsilateral to that eye. But since door and trees subtended an angle of only $3^{\circ}$ bilaterality of these signals was likely. The subjects were asked to fixate a knob in the centre of the door. The synoptophore tubes were first adjusted so that the slides fused. The subject then saw a single house with a large tree to the right (viewed by the left eye) and a small tree to the left of the door (viewed by the right eye). The tubes were then separated; thereupon the subject's eyes diverged by up to $5^{\circ}$ in order to preserve fusion. Within each slide the door and the tree remained fixed in relation to each other, yet subjects gained a very strong impression that one of the trees moved towards the door.

In the test the eyes were made to move in opposite directions. Ocular motor signals about lateral movements of each eye are probably organised in the hemisphere contralateral to that eye. ${ }^{17}$ In our test the trees were viewed in the nasal field of each eye; hence retinal signals about the trees were projected to the ipsilateral hemisphere. Yet for most people movement information deriving from one eye was successfully associated with retinal signals about the tree seen by that eye, presumably employing interhemispheric connections. This gave rise to the consistent illusion that one, but only one, of the trees moved. Retinal and ocular motor signals derived from the other eye were not associated in this way, and the tree seen by the other eye did not appear to move. Hence this version of the Dunlop test seems to 
Fig. 1 Results of studies on normal readers and dyslexic children.

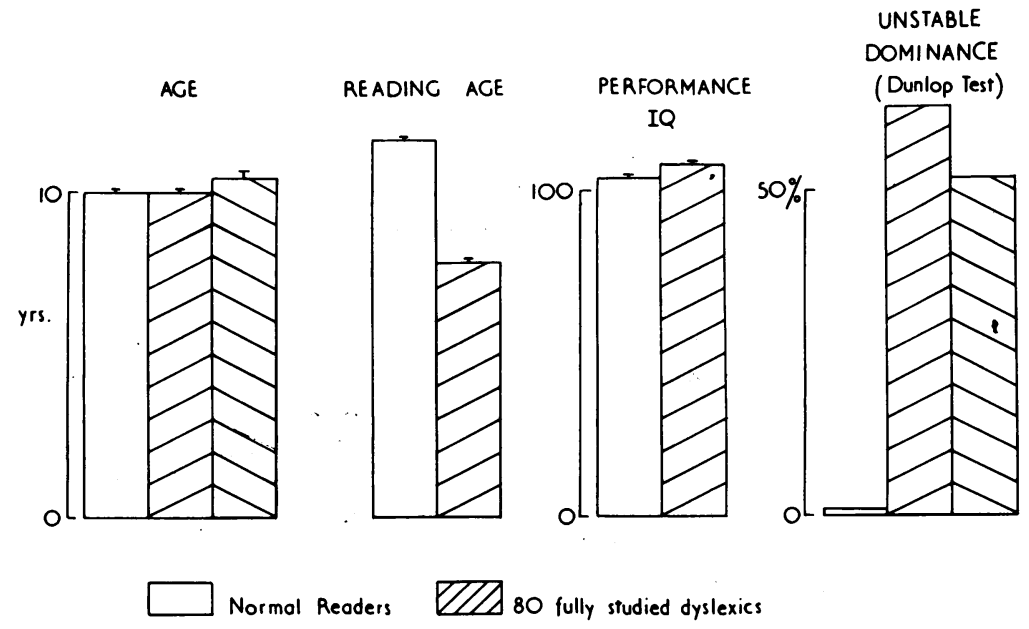

MIV 274 Orher dyslexics

be able to identify the eye whose ocular motor and retinal signals are successfully associated (i.e., the eye contralateral to the tree that appeared to move) as the dominant one, under conditions analogous to those found when reading.

To assess the reliability of such ocular motor-retinal association the Dunlop test was repeated 10 times in each child, the slides being changed round frequently to prevent the child from guessing, but keeping the trees in the nasal field of each eye. If the test located the dominant eye on the same side 8 or more times out of 10, the subject was said to show 'fixed' or 'stable' dominance; otherwise it was termed 'unstable' or 'unfixed.' Stable dominance was said to be 'uncrossed' if the dominant eye was on the same side as the hand preferred for writing and 'crossed' if it was not. Only in a very small proportion of children could the dominant eye not be ascertained owing to lack of co-operation or suppression of the image from one eye.

\section{Results}

Fig. 1 shows some of the results of these studies. It will be noted that, while the 80 fully studied dyslexics and the 80 normal children had very similar mean ages and nonverbal IQs, the average reading age of the dyslexics was almost 4 years behind that of the controls. The mean reading age of the dyslexics was almost 10 standard errors behind that of the controls. ${ }^{18}$

The mothers of 116 of 354 reading-retarded children $(33 \%)$ reported that theirs had been a 'difficult' birth (premature, low birth weight, excessively long or short labour, fetal distress, or other memorable obstetric problem). 124 (35\%) reported a close relative (parent, grandparent, or sibling) with reading problems.

No consistent differences between dyslexic and normal children could be discerned on routine ophthalmological or orthoptic investigations apart from a slight excess of mild esophoria amongst the dyslexics. This has been found in many studies. ${ }^{5}$ It may be taken as another sign of ocular motor immaturity. Visual acuity was usually normal and equal in both eyes. Neither amblyopia, suppression, convergence insufficiency, nor manifest squint were commoner among dyslexics.

The results of the Dunlop test were clear, however. $50(63 \%)$ of the 80 fully studied dyslexics and 142 of the other $274(52 \%)$ (i.e., $54 \%$ of all the children with backward reading who were examined) had failed to develop stable ocular motor dominance, whereas only one normal reader (in fact low normal) showed unstable dominance on this test. Moreover afterwards we found that, of the dyslexics whose reading errors had been assessed, all those who lacked stable dominance had been classified as 'visual.'

Crossed dominance was less than half as common in the dyslexics $(18 \%)$ as in the normal children $(41 \%)$, because such a high proportion of dyslexics had unstable eye dominance. Among dyslexics with stable eye dominance and normal readers crossed and uncrossed dominance was found to be almost equally common (see Orton ${ }^{19}$ and Zangwill ${ }^{20}$ ).

\section{Discussion}

In the controlled study neither the children nor ourselves were informed which subjects were normal nor which were dyslexic, 'visual,' or 'nonvisual' until after we had tested them. Yet the Dunlop test 
established clearly that those whose reading problems appeared mainly visual had failed to develop stable ocular motor dominance. We conclude therefore that the test is a reliable and objective method of diagnosing 'visual' dyslexia. Since it is a test which does not involve reading itself but demands similar retinal/ocular motor associations to those required for reading, the results suggest that one of the difficulties visual dyslexics may face is a failure to develop stable ocular motor dominance. Hence they may not be able reliably to determine where the letters they see are located. Ocular motor/retinal association problems may thus help to account for perhaps half to two-thirds of cases of dyslexia.

Much evidence suggests that dyslexia sometimes results from mild birth trauma (35\% of our series) or a genetic trait $(33 \%)$, either of which may lead to abnormal cerebral lateralisation. Dyslexic children may lack the normal right ear advantage for comprehending verbal material in dichotic listening tests. ${ }^{21} 22$ The difference between their right and left half fields when identifying tachistoscopically presented written material is said to be greater than normal. ${ }^{2324}$ They may not show the normal left half field superiority for recognition of faces, ${ }^{25}$ and they often lack the normal right-hand advantage for dichaptic (tactile) recognition of letter shapes. ${ }^{26}$ They may show unusual patterns of hand, foot, and eye preference. ${ }^{202627}$ The visual evoked potentials ${ }^{28}$ and electroencephalograms $^{29}$ recorded over the left hemisphere of dyslexics may differ from those of normal controls. Among them there is even an unusually large number of right handers with anticlockwise hair whorls. ${ }^{30}$ However, all the differences reported have been small, there is much disagreement between studies, and the most that can safely be said is that dyslexics probably do suffer mild abnormalities of cerebral .lateralisation.

Our demonstration that up to two-thirds of dyslexic children fail to establish stable ocular motor dominance with respect to foveal vision is therefore not entirely unexpected. However, our results are clearer than many, and it is easy to understand how failure to develop ocular motor lateralisation may lead to inexact localisation of letters, hence difficulty with reading. We may speculate that it is this neurologically based failure of perfect association of retinal with ocular motor signals which leads to the abnormalities of dyslexics' eye movement control which are observed. The circumstances under which abnormal eye movements can be demonstrated in these patients (when they are attempting to make smooth pursuit movements, small visually triggered saccades, or fixate under visual control) all demand accurate association of retinal with ocular motor signals dealing with the central few degrees of visual angle.
Thus it appears that failure to develop dependable ocular motor dominance, as revealed by repeated Dunlop testing, may confuse the ocular motor system of dyslexics at all times, not just when they are trying to read.

Our thanks are due to $\mathrm{Mr} \mathrm{J}$. McMillan under whose care these children were, and to $\mathrm{Mr} \mathrm{D}$ Brownhill for much useful help and advice.

\section{References}

1 Vellutino FR. In: Benton AL, Pearl D, eds. Dyslexia. New York: Oxford University Press, 1978.

2 Zangwill OL, Blakemore CB. Dyslexia-reversal of eye movements during reading. Neuropsychologia 1972; 10: 371-3.

3 Rubino CA, Minden HA. An analysis of eye movements in children with reading difficulties. Cortex 1973; 9: 217-20.

4 Tinker M. Studies of eye movements during reading. Psychol Bull 1958; 55: 215-31.

5 Dunlop P. Dyslexia. The orthoptic approach. Aust Orthopt J 1972; 12: 16-20.

6 Bettman JH, Stern EL, Whitsel LJ, Goodman HF. Cerebral dominance in dyslexia. Arch Ophthalmol 1967; 78: 722-9.

7 Grinberg DA, Stark L. Eye movements, scan paths and dyslexia. Am J Optom Physiol Opt 1978; 55: 557-70.

8 Pavlidis GT. Dyslexic's erratic eye movements. Dyslexia Rev 1978; $1: 22-8$.

9 Porta IB. De refractione. Naples: Carlinus. 1593.

10 Walls GL. A theory of ocular dominance. Arch Ophthalmol 1951; 45: 387-412.

11 Ogle KN. Ocular dominance and binocular retinal rivalry. In: Davson H, ed. The Eye. New York: Academic Press, 1968: 4.

12 Berlucchi G. Anatomical and physiological aspects of visual functions of the corpus callosum. Brain Res 1972; 37: 371-92.

13 Motter BC, Mountcastle VB. Functional properties of light sensitive neurones in posterior parietal cortex. J Neurosci 1981; 1: 3-26.

14 Benton CD, McCann JW. Dyslexia and dominance. J Pediatr Ophthalmol 1959; 6: 220-7.

15 Helveston EM, Billips WC, Weber JC. Controlling eye/dominant hemisphere relationships as a factor in reading disability. $A m J$ Ophthalmol 1976; 70: 96-100.

16 Porac V, Coren S. The dominant eye. Psychol Bull 1976; 83: 880-97.

17 Mott FW. Shafer E. Eye movements produced by cortical faradisation in the monkey. Brain 1980; 13: 165-73.

18 Rutter $M$, Yule $W$. The concept of specific reading disorder. J Child Psychol Psychiatry 1975; 16: 181-97.

19 Orton S. Reading, Writing and Speech Problems in Children. London: Chapman and Hall, 1937.

20 Zangwill OL. Cerebral Dominance and its Relation to Psychological Function. Edinburgh: Oliver and Boyd, 1960.

21 Kimura D. Speech lateralisation in young children determined by an auditory test. J Comp Physiol Psychol 1963; 56: 89-92.

22 Bakker DJ. Hemispheric specialisation and the stages of learning to read. Bull Orton Soc 1973; 23: 15-27.

23 Marcel V, Rajan P. Lateral specialisation for the recognition of words and faces in good and poor readers. Neuropsychologia 1975; 13: 489-97.

24 Yeni-Komshian GH, Isenberg P, Goldberg H. Cerebral dominance and reading disability-a left field defect in poor readers. Neuropsychologia 1975; 13 : 83-94.

25 Witelson SF. In: Harnard S, ed. Lateralisation in the Nervous System. New York: Academic Press, 1977.

26 Goldberg HK, Amott W. Ocular motility in learning disorders. J Learning Disabilities 1970; 3: 160-6. 
27 Kornmann R. Brauch L. Hills U. Riemer C. Schwender V. Praeferenz and Leistungs Dominanz der Hande bei Lernbehinderten Sondershulern. Z Haelpedagogik 1974: 25: 147-56.

28 Conners CK. Cortical visual evoked potentials in children with learning disabilities. Psvchophvsiologv 1970: 7: 418-28.
29 Sklar B. Hanly J. Simmons WW. An EEG experiment aimed toward identifying dyslexic children. Nature 1972: $241: 414$.

30) Tjossem TD. Hansen TJ. Riplev HS. (1961): Reading difficulties in young children. Reported at $117_{\text {th }}$ meeting of American Psychiatric Association. Chicago. 